\title{
Power Quality Issues in Variable Speed Wind Turbine and Application of STATCOM
}

\author{
Rakshita R. Upadhyay ${ }^{1}$, Ch. V. Sivakumar ${ }^{2}$ \\ ${ }^{1}$ P.G Student, Parul University, Limda, Waghodia \\ ${ }^{2}$ Assistant Professor, Parul University, Limda, Waghodia
}

\begin{abstract}
In this paper a $8.5 \mathrm{KW}$ rated PMSG based wind energy system is designed and its power quality issues are discussed. A diode-rectifier based topology is used with Boost converter for wind turbine. Possible solutions to mitigate the power quality problems are also defined. The best possible solution is by using FACTS devices. Here a STATCOM with DQ control is designed for application in wind system. This shows that if we use STATCOM with the wind energy system then power quality issues can be mitigated. The system is simulated in MATLAB/SIMULINK environment.
\end{abstract}

Keywords: Power quality, PMSG, STATCOM, DQ control, boost converter, MPPT, MATLAB

\section{Introduction}

The use of renewable energy is leads to the new era in the power system and gives economical and technical benefits. The total wind power installed capacity was $24,677 \mathrm{MW}$ as of August 31, 2015. The global wind power statics shows that by the end of 2016 the wind power capacity will reach just under $500 \mathrm{GW}$. The increase growth of renewable leads to study about the wind turbine technologies and the problem wind farm faced.

\subsection{Power quality issues}

\subsubsection{Voltage Variation}

The voltage variation issue results from the wind velocity and generator torque. The voltage variation is directly related to real and reactive power variations. The voltage variation is commonly classified as under:

- Voltage Sag/Voltage Dips.

- Voltage Swells.

- Short Interruptions.

- Long duration voltage variation.

The voltage flicker issue describes dynamic variations in the network caused by wind turbine or by varying loads. Thus the power fluctuation from wind turbine occurs during continuous operation.

\subsubsection{Harmonics}

The harmonic results due to the operation of power electronic converters. The harmonic voltage and current should be limited to the acceptable level at the point of wind turbine connection to the network. To ensure the harmonic voltage within limit, each source of harmonic current can allow only a limited contribution,

\subsection{IEC 61400-21 standards and grid code requirement}

The rules for realization of grid operation of wind generating system at the distribution network is defined as - per IEC61400-21. To ensure the safe operation, integrity and reliability of the grid is almost important.
Voltage Rise (u) -The voltage rise at the point of common coupling can be approximated as a function of maximum apparent power $S_{\max }$ of the turbine, the grid impedances $\mathrm{R}$ and $\mathrm{X}$ at the point of common coupling and the phase angle $\Phi$. The Limiting voltage rise value is $<2 \%$

Voltage dips (d) - The voltage dips is due to start-up of wind turbine and it causes a sudden reduction of voltage. The acceptable voltage dips limiting value is $\leq 3 \%$.

Flicker-The measurements are made for maximum number of specified switching operation of wind turbine with 10minutes period and 2-hour period are specified. The Limiting Value for flicker coefficient is about $\leq 0.4$, for average time of 2 hours.

Harmonics - The THD limit for $132 \mathrm{KV}$ is $\leq 3 \%$.

Grid frequency- The grid frequency in India is specified in the range of $47.5-51.5 \mathrm{~Hz}$, for wind farm connection. The wind farm shall able to withstand change in frequency up to $0.5 \mathrm{~Hz} / \mathrm{sec}$. Thus the requirements in the Grid Code can be fulfil the technical limits of the network.

This paper proposed a design of PMSG and its power quality issues with a solution-STATCOM. A STATCOM is control with dq control method and gives unity power factor at load side. The rectifier block of power conditioning block is keeping uncontrolled while inverter is gating signal with PWM technique.

\subsection{Permanent Magnet Synchronous Generator}

A permanent magnet synchronous generator is a generator where the excitation field instead of a coil permanent magnet is provided. A power conditioning system is connected to wind turbine and $\mathrm{AC}$ output is provided to grid. Fig(1) shows basic block diagram of wind system.

Three type of power conditioning system are provided. Here a diode rectifier-boost converter topology is considered. It has an advantage of reduction in cost and it has simple 


\section{International Journal of Science and Research (IJSR) \\ ISSN (Online): 2319-7064}

Index Copernicus Value (2013): 6.14 | Impact Factor (2015): 6.391

construction. A MPPT technique can be applied here to extract maximum power.

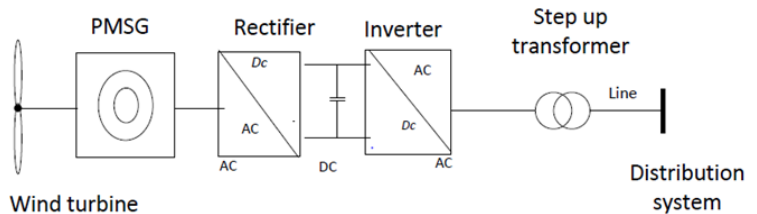

Figure 1: Permanent Magnet Synchronous Generator

\subsection{Static Synchronous Compensator (STATCOM)}

A STATCOM is a controlled reactive-power source. STATCOM is a VSC based device which provides both active and reactive power. A STATCOM is capable of improving power system performance in various areas; such as

- The dynamic voltage control in transmission and distribution systems;

- The power-oscillation damping in power-transmission systems;

- The transient stability;

- The voltage flicker control; and

- The control of not only reactive power but also (if needed) active power in the connected line, requiring a dc energy source.

- STATCOM can improve power quality.

\section{System Configuration}

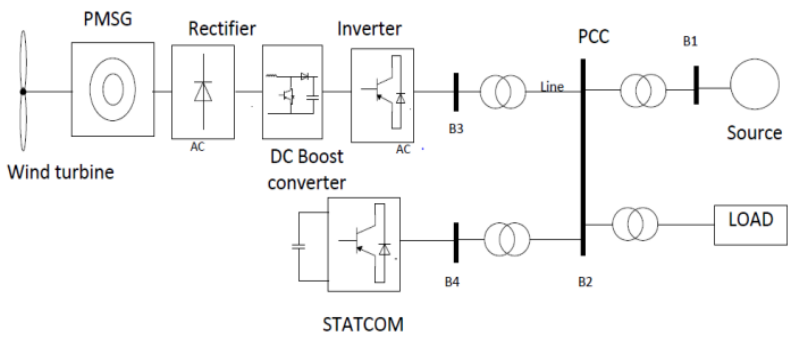

Figure 2: Grid Connected Wind Energy System with STATCOM

\subsubsection{Wind Energy System}

The wind turbine is used to generate rotating mechanical power output from the given wind speed. Mostly wind turbine are designed with 2 or 3 blades but Two blades cost less than three blades, but two-bladed wind turbines must operate at higher rotational speeds than three-bladed wind turbines. The power of the wind in area A, perpendicular to the wind direction is given by formula

$$
P \text { mech }=\frac{1}{2} \rho A V^{3} C p
$$

The fraction of the wind turbines is given by factor $\mathrm{Cp}$, called the power coefficient. It has theoretical Betz limit of 59.3\%.

$$
C_{p}\left(\lambda_{2} \beta\right)=C_{1}\left\{C_{2}\left(\frac{1}{\lambda_{i}}\right)-C_{a} \beta-C_{4}\right\} e^{-c_{5} / \lambda_{i}}+C_{6} \lambda
$$

The coefficients $C_{1}-C_{6}$ can be different for various turbines. They depend on the wind turbine rotor and blade design. The parameter $\frac{1}{\lambda_{i}}$ is defined as

$$
\frac{1}{\lambda_{\mathrm{i}}}=\frac{1}{\lambda+0.08 \beta}-\frac{0,025}{\beta^{3}+1}
$$

$$
C_{1}=0.5, C_{2}=116, C_{\mathrm{a}}=0.4, C_{4}=5, C_{5}=21 \text {, }
$$$$
C_{6}=0.0068
$$

Two mass drive model is also designed here for transmit rotational motion of the turbine rotor to the electrical generator. The drive train of wind turbine generator system consists of blades, rotor shaft, gearbox, and generator. The wind turbine is controlled by pitch angle control technique. Pitch angle control controls the vertical position of the turbine that will spill uncontrolled power. The Power conditioning system composed of uncontrolled rectifier, DC boost converter and inverter. A generator of $8.5 \mathrm{KW}$ has been developed here.

\subsubsection{Power Conditioning System}

The machine side converter is of diode rectifier topology employing with 6 diodes, a DC chopper, and inverter topology. An uncontrolled diode rectifier cascaded by boost converter is used as MSC to save cost The variablemagnitude- variable frequency ac power from the WT generator is firstly converted to a dc power by means of a diode rectifier circuit and then is converted back to an ac power at desired frequency and voltage level by means of a grid-side controlled inverter The boost converter utilised on the dc side has two advantages - firstly, the ease in maximum power point tracking(MPPT)and secondly, the improved flexibility in GSC control. The control of a variable-speed PMSG by a diode rectifier cascaded by a dc chopper is proposed. The grid side converter is SPWM type inverter and the power is fed to the grid.

\subsubsection{Perturb and Observe Method Based MPPT}

A perturb and observe algorithm is used to maximising the output power of variable speed wind turbine. By varying the duty cycle with small amount we can get the maximum power output. The proposed $\mathrm{P} \& \mathrm{O}$ algorithms use adaptive perturbation step sizes and adaptive observation periods. A proposed algorithm is shown here. Generated switching signal is fed to the boost converter switch and maximum power output is extracted.

\section{Control System}

The control system has to generate pulse for the STATCOM. The first conversion take place is conversion of $\mathrm{VABC}$ in to VDQ0. This is the standard conversion of three phase to two phase by reference frame theory and similarly we also have a reference source. Both the actual and reference signal are converted in to DQ0. This error signal is further converted into $\mathrm{ABC}$ and known as error signals. Error signals are fed to SPWM pulse generator for gating pulse for inverter. The filters can connect additionally to remove harmonics. 


\section{International Journal of Science and Research (IJSR) \\ ISSN (Online): 2319-7064}

Index Copernicus Value (2013): 6.14 $\mid$ Impact Factor (2015): 6.391

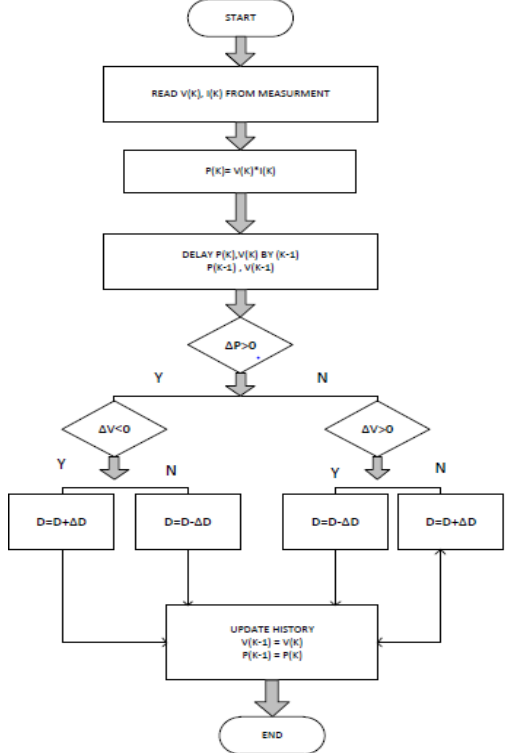

Figure 3: Perturb and Observe MPPT

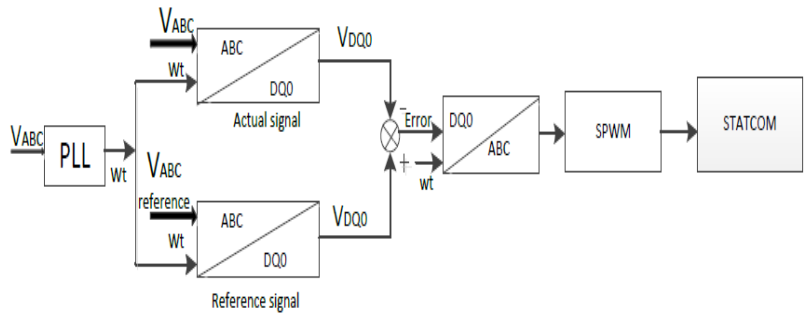

Figure 4: STATCOM Control Scheme

This control strategy gives accurate switching to the STATCOM and thus the uninterrupted output and unity power factor is getting.

\subsection{Phase Lock Loop (PLL)}

A PLL is a device that provides tracking of one signal by another one. As a result of this tracking, the output signal is synchronized with the input reference signal in phase and frequency. It is used to compare two frequencies and results the input frequency is equal to the output frequency. Also it is used to provide rotational frequency at direct and quadrature components. A low pass filter is used to eliminate high frequency.

\subsection{Switching Signal}

The switching signals are generated by comparing one actual signal with the reference signal. This error signal is further converted to 3-phase variable $\mathrm{ABC}$ and fed to the inverter for generating SPWM pulses.

\section{Simulation and Result}

Two different type of simulation is carried out here. (1) PMSG based wind energy system and (2) STATCOM simulation.

\subsection{Wind Energy System}

From the equations (1) to (4) the wind turbine subsystem is created and provided wind speed is varies with time. And also pitch angle is kept as 0 .

A two mass drive train is also simulated here and the torque is given to the PMSG machine. The rotor speed and torque output is shown in fig (8).

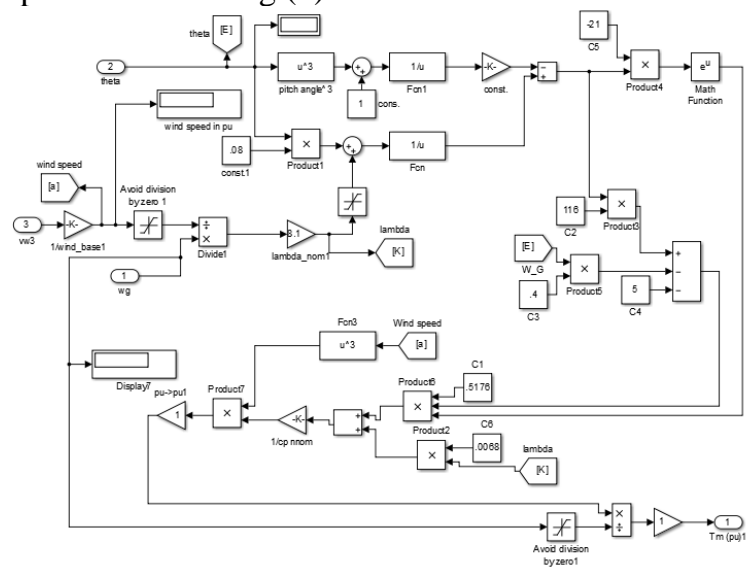

Figure 5: Wind Turbine Modelling

Fig (9) shows a wind energy system with power conditioning block. Firstly PMSG's output is converted to the DC and then a Boost converter is used for DC-DC power conversion and finally a SPWM based inverter converter provides AC power to the load

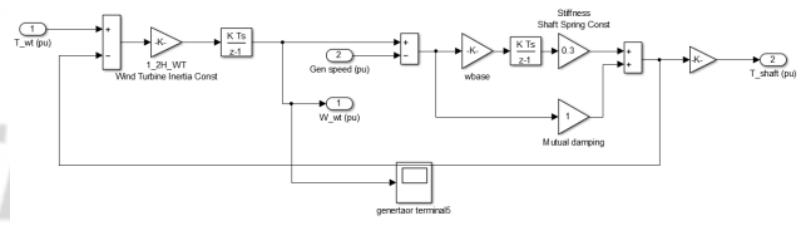

Figure 6: Drive Train Modelling

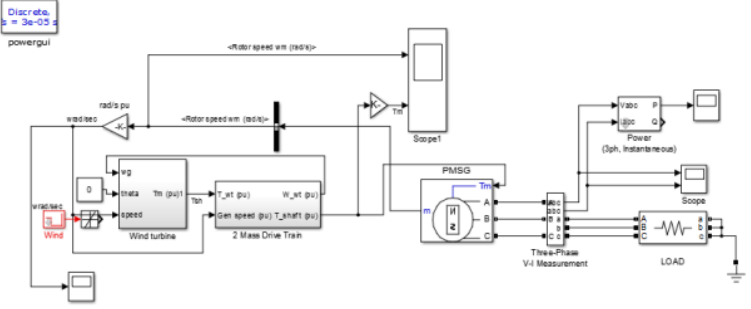

Figure 7: Wind Energy System

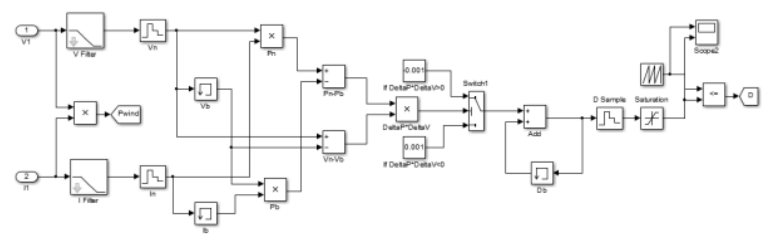

Figure 8: P \& O MPPT Simulink Model 


\section{International Journal of Science and Research (IJSR) \\ ISSN (Online): 2319-7064 \\ Index Copernicus Value (2013): 6.14 | Impact Factor (2015): 6.391}

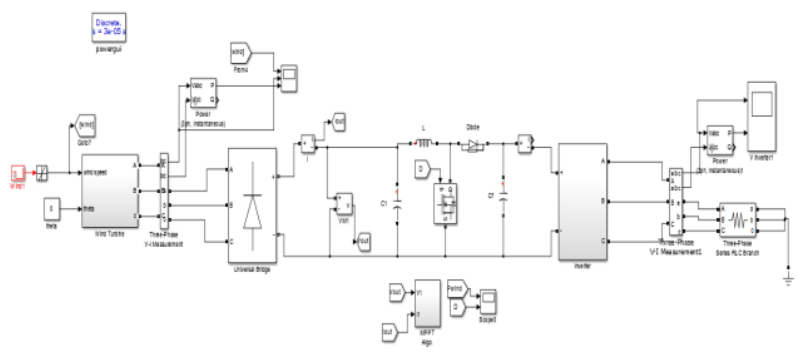

Figure 9: Wind Energy System with Power Converter Topology

The rotor speed and torque output is shown in fig(11). The output voltage, output power is shown in fig (12). It means that if the wind speed is vary the output power is also varies and therefore we get fluctuating power which can be smoothen by STATCOM.

\subsection{STATCOM Control System}

A source is connected to the 3 phase load. A reference voltage source is provided to generate error signal with actual source is shown in fig (10). Whenever sag produce in the system a STATCOM will compensate it with the generated error signal. The simulation is carried out for 1 p.u system. Fig (13) shows the supply voltage, generated error signal and compensated error signal. The THD value for the system is $2.74 \%$.It is shown in fig (14).

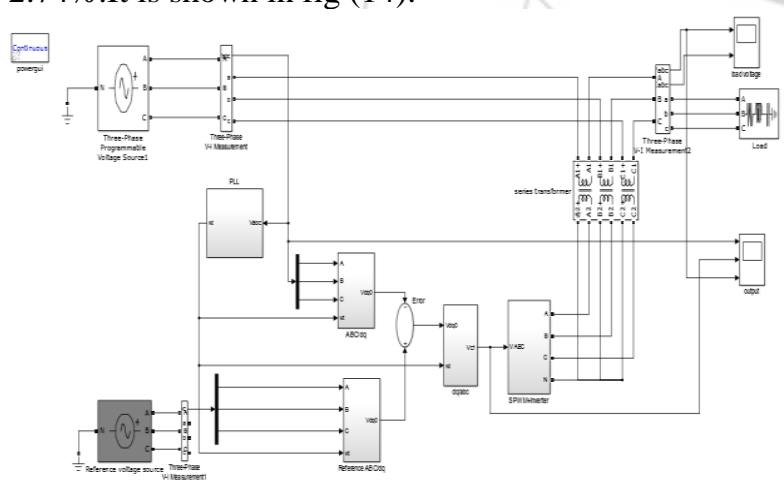

Figure 10: STATCOM Simulink Model

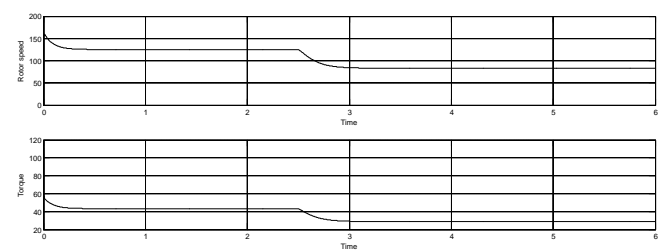

Figure 11: Wind System Output (i) Rotor speed (ii)Torque

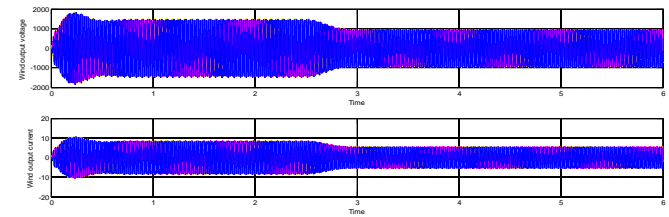

Figure 12: Output from wind system (i)voltage and (ii)current

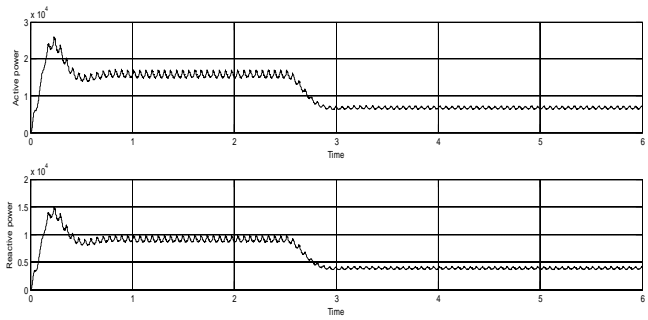

Figure 13: Output from wind system(i)active power and (ii)reactive power



Figure 14: STATCOM Compensation (i) Supply voltage (ii) Error signal (iii) Load voltage

Result shows that the power quality of wind turbine can be mitigate with the application of STATCOM. STATCOM connected to load will compensate voltage into the line.

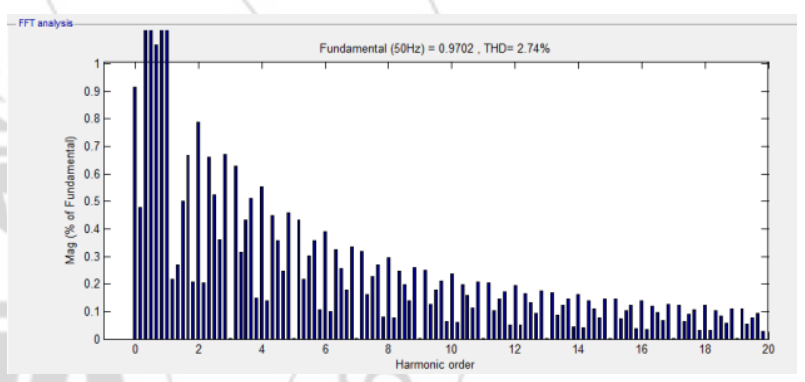

Figure 15: $\mathrm{THD}=2.74 \%$

\subsection{STATCOM with Wind Energy System}

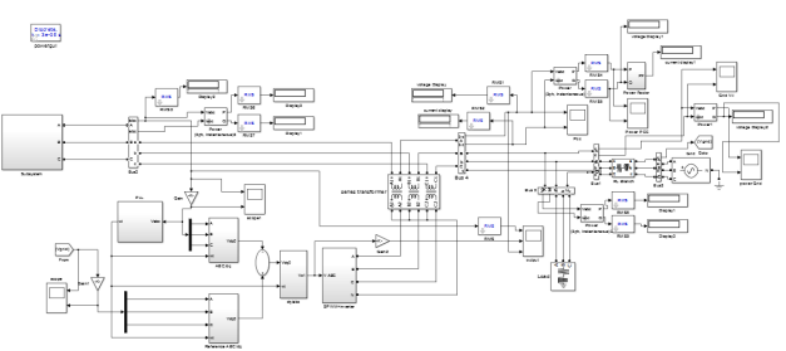

Figure 16: Wind energy system with STATCOM

Here a wind energy system is connected to a grid and for power quality improvement a STATCOM is connected to improve power quality. The fig 16 shows the basic block diagram of the system and the output is shown in figure 17.

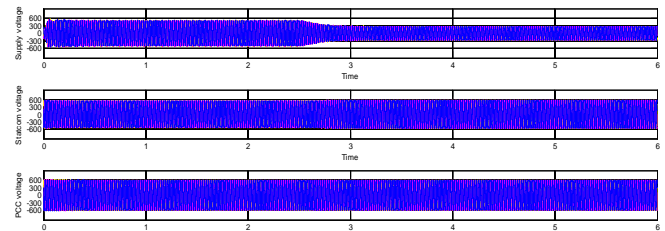

Figure 17: wind system (i)input voltage (ii)STATCOM injected voltage and (iii)output voltage

\section{Volume 5 Issue 5, May 2016}




\section{International Journal of Science and Research (IJSR) \\ ISSN (Online): 2319-7064}

Index Copernicus Value (2013): 6.14 | Impact Factor (2015): 6.391

\section{Conclusion}

A PMSG based wind energy system has a better performance and its simulation is carried out here and also a simulation of STATCOM is carried out. The STATCOM will improve the voltage profile and this can be used as application in wind energy system to mitigate power quality issues.

\section{References}

[1] Sharad W. Mohod, Mohan V. Aware, (2010) "A STATCOM-Control Scheme for Grid Connected Wind Energy System for Power Quality Improvement," IEEE Trans. On Energy Conversions.vol. 4, no 3, pp. 346 352R. Caves, Multinational Enterprise and Economic Analysis, Cambridge University Press, Cambridge, 1982. (book style)

[2] S. W. Mohod and M. V. Aware (2006), "Grid power quality with variable speed wind energy conversion" in Proc. IEEE Int. Conf. Power Electronic Drives and Energy System (PEDES), Delhi

[3] R.A kantaria , s.k.joshi, k.r.siddhpura (2011) "A novel hysteresis control technique of VSI based STATCOM" in Proc. IEEE Int. Conf Power Electronics (IICPE), India International Conference on power electronics

[4] Kedar Patil, Bhinal Mehta, (2014) "Modeling and Control of Variable Speed Wind Turbine with Permanent Magnet Synchronous Generator" in Proc. IEEE Int. Conf on Advances in Green Energy (ICAGE), 17-18, Trivandrum

[5] M. M. Chowdhury, , M. E. Haque, A. Gargoom, and M. Negnevitsky, (2012) "A Direct Drive Grid Connected Wind Energy System with STATCOM and Supercapacitor Energy Storage" in Proc. IEEE Int. Conf Power System Technology (POWERCON), Auckland

[6] M.P.Donsión, J.A. Güiemes, J.M. Rodríguez, (2007) "power quality. Benefits of utilizing facts devices in electrical power systems" in Proc. IEEE Int. Conf on Electromagnetic Compatibility and Electromagnetic Ecology, Saint-Petersburg

[7] A. Adamczyk, R. Teodorescu, R.N. Mukerjee, P. Rodriguez (2010) "Overview of FACTS Devices for Wind Power Plants Directly Connected to the Transmission Network", IEEE.

[8] S.M.Tripathi, A.n.Tiwari, Deependra singh(2015) "Gridintegrated permanent magnet synchronous generator based wind energy conversion systems: A technology review", Renewable and Sustainable Energy Reviews, ScienceDirect.

[9] M. Nasiri,J, Milimonfared , S.H.Fathi (2015) “A review of low-voltage ride-through enhancement methods for permanent magnet synchronous generator based wind turbines", ScienceDirect.

[10] M. M. Chowdhury, M. E. Haque, A. Gargoom, and M. Negnevitsky, (2013) "Performance Improvement of a Grid Connected Direct Drive Wind Turbine Using Super-capacitor Energy Storage",IEEE

\section{Author Profile}

Rakshita Upadhyay: received the B.E. and M.E. degrees in Electrical Engineering from Vadodara Institute of Engineering in 2014 and Parul university in 2016, respectively.

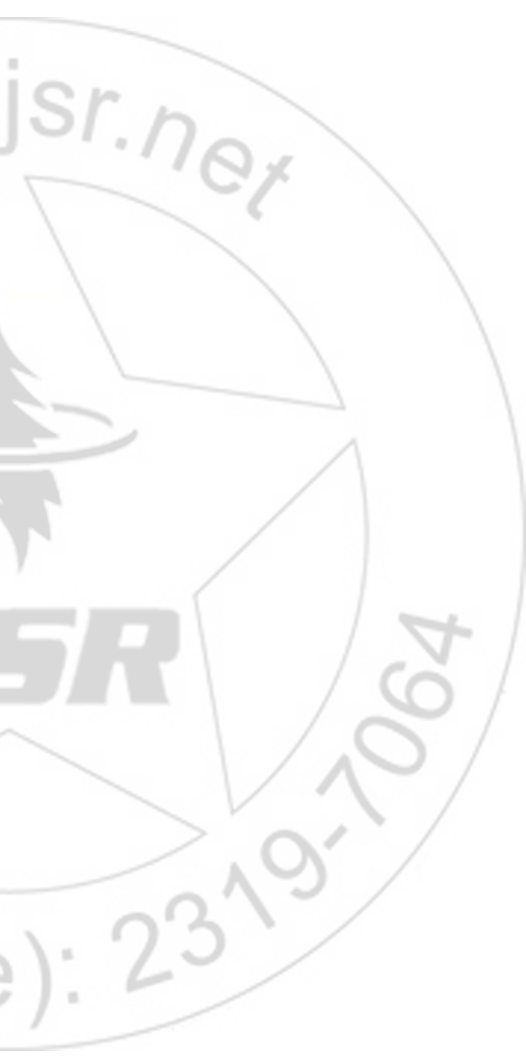

